who understands the problems of human performance, and the engineer or technologist, who understands machines, so that the best machine for the purpose can be designed and built-Fitting the Machine to the Man.

Some examples will be given.

In regard to disabled people, the physicians and surgeons who deal with these problems have always made a special study of the disabilities and various ways of overcoming them. Today Ergonomics can take this process a step further and bring engineering design and human biology together in a systematic way, with a large and growing body of knowledge of human performance behind it.

\title{
SOME PRINCIPLES IN WHEELCHAIR DESIGN
}

\author{
By BIRger RoOs \\ Szuedish Central Committee for the Care of the Disabled, Stockholm \\ Development Department for Technical Aids
}

THE very severly disabled are often very difficult to fit successfully with a standard model of wheelchair, even after alterations to the chair. Some of the work at S.V.C.K. Technical Division is devoted to the design of special wheelchairs for such cases.

One of the fundamental questions to be answered before beginning the design work is - what particular feature does the disabled require of his wheelchair? The following are some of the main features to be considered: comfortable sitting for long periods, good working position and self-lifting and easy handling of the chair into and out of a car.

To combine all these features in one chair is almost impossible. Our experience shows that the best results are accomplished by having two or more chairs for every individual. I am going to devote part of this paper to the third point: selflifting and easy handling of the chair into and out of a car.

The need for another person's help can be greatly reduced if the wheelchair of a handicapped car driver incorporates certain aspects. In our work, we have started from the point that a standard car should be used with as few alterations as possible. We know that even with Servo-equipment and hand controls the driving of the car is almost impossible for many. The transferring of the body is in itself a big problem but it can be solved by some means or other. However, even very light collapsible chairs are too heavy and, perhaps more important, too bulky. After some tests we found that a chair which could be handled by some of our handicapped car drivers should weigh not more than approximately io lb., and the size of the chair should be approximately 5 inches by 20 inches by 20 inches. Starting from these premises, it seems to be impossible to make a collapsible chair in one piece, particularly if this chair has to be fitted with big wheels so that the wheelchair user can propel himself. It seemed to be necessary, therefore, to build the chair in sections. The problems was to find a suitable way of doing this and at the same time make the chair easy to handle. For two years we have been trying to develop such a system with two types of chair.

These two chairs are almost identical. It is possible to divide them into three parts-two side sections with wheels and a third consisting of seat and backrest 
with arm supports. Each side section is joined to the seat by two cones. This gives a light, rigid and clean design.

The footrests are adjustable in height and can be lowered to the ground, thus making it possible for the patient to stand up from the chair and also to sit down more easily. The seat and backrest are made of polyester resin and fibreglass in one piece. The arm supports can be folded upwards. During assembly the side sections are held in correct position by a cross-bar. The chair is symmetrical in the way that the seat can be turned $180^{\circ}$, thus transferring the big wheels to the rear. Full details of the design are not yet finished, but we have already found that many disabled car drivers with weak arms and backs can use these chairs successfully. Figure I shows a protype of the special design. For use outdoors and particularly

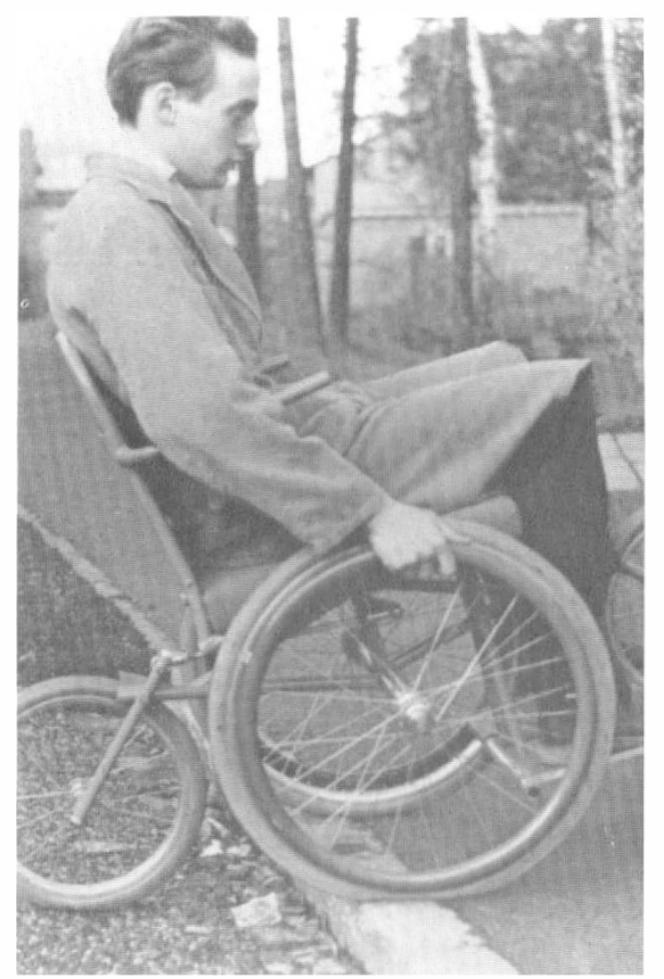

FIG. I

on rough surfaces with obstacles such as kerb-stones, many conventional chairs are useless. The reasons are many but one of the most important is that the small wheels are too small. Another is that many wheelchair users cannot accomplish the technique of balancing on the rear wheels.

In this chair, the seat is placed centrally over the big wheels. Two supporting wheels of $\mathrm{I}_{4}$ inches in diameter, one in front and another at the rear, are mounted in such a way that one of these wheels is free of the ground when the other is on the ground. The clearance is approximately one inch. After some training, it is possible to make turns with the chair, balancing on the big wheels. When a kerb 
has to be mounted the supporting wheels are moved forwards and backwards at the same time as they move upwards. As the centre of gravity is just over the big wheels, the total supporting base of the chair is very wide and it is relatively easy to climb the kerb without any risk of turning over.

Figure 2 shows a special chair under construction. The chair is made for a very disabled boy who needs to be able to sit comfortably.

For people with problems of high degree of sensitivity to pressure when sitting, we have tried soft air-rubber cushions. The maximum pressure against the body is $0.5 \mathrm{lb}$./sq.inch.

Based on the idea of electronic by-pass control developed at Stoke Mandeville Hospital, we have made a similar control for electric wheelchairs (fig. 3). We are

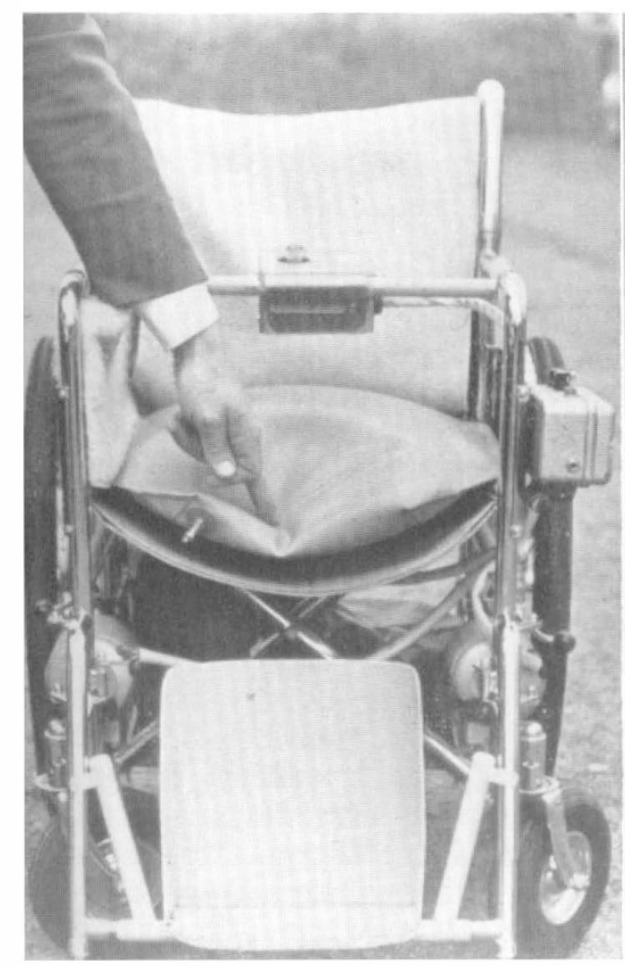

FIG. 2



FIG. 3

using four pneumatic impulses stimulated by mouth, one high and one low pressure blow and one high and one low pressure suck. Running forwards is achieved by a strong blow, backwards by a strong suck. Turning right a slight blow turning left a slight suck. The relay circuits are designed in such a way that running forwards and backwards is obtained by short impulses, but the turn-around impulses must be applied through the whole turn. With this system, it is possible during running forwards and backwards to correct the course by slight blowing and sucking. Rotation right or left is also possible. This system has been tried out only to a very limited extent, but the results are very promising. The boy for whom the model has 
been designed had no difficulty in controlling the wheelchair, once he had been given the instructions.

\title{
EMPLOYMENT FROM A WHEELCHAIR
}

\author{
By Charles Dunham \\ General Secretary, British Limbless Ex-Service Men's Association
}

You may wonder why I as a fairly mobile amputee should have accepted an invitation to speak about employment from a wheelchair-the explanation is that my Association is especially interested in all forms of employment and rehabilitation of the physcially handicapped and we have some experience of the problems of wheel-chair users, expecially double leg amputees and others with severe leg wounds.

As I see it, this question of employment can be divided into two issues-the one is employment or living within the patient's home and the other outside employment in normal industrial conditions. Whichever section is considered, there is overall an immediate requirement for the wheelchair to be suited to the needs of the user. It is essential that the chair should be comfortable, light and easy to handle, either by the patient or his assistant. The wheelchair for the severely disabled is not just a means of getting about, it is an extension of his body and one which is put on test all day, every day. Others will be speaking on the necessity for individual assessment of the types of work for which particular categories of disabled are best suited and of the principles in designing wheelchairs. I merely emphasise the relationship between the user and his chair and the fact that, in our view, the approach to assessment of working ability is the extent of the ability left to the individual and how best this might be developed rather than the degree of his disablement.

More and more we find in today's modern, scientific and technical age that man need no longer rely upon his physical strength alone to live or to work effectively. All over the country, and indeed in many areas of the world, we find persons with severe physical disablement and chronic disease working effectively and doing jobs which but a few years ago would have been considered impossible for them. One reason for this has been the development of modern engineering and other techniques, more and more of the energy needed to operate machines, for example, is provided by the machine itself, and the physical demands on the operator are that much less. One would wish that this new approach to industrial techniques and organisation and methods could be more widely applied and the good examples of the few tirms followed more closely. Unfortunately one often finds that employers tend to give preference in employment to those with comparatively minor disabilities because they, often quite erroneously, think there is no easy solution for the employment of the wheelchair user. The architectural barriers, the difficulties which the wheelchair user faces in everyday life in public and other buildings are immense. Sedentary occupations which would otherwise be eminently suitable are often quite impossible because the works or offices are built up a pile of steps, with no ramps. difficult doorways and frequently no lifts. When these obstacles are overcome there are the difficulties of doing the job itself. This calls for under- 